\title{
PENERAPAN METODA SIX SIGMA DENGAN PENDEKATAN DMAIC UNTUK MENGURANGI BIAYA KEGAGALAN INTERNAL PADA PRODUKSI KANTONG SEMEN PASTED BAG DI PABRIK KANTONG PT. SEMEN PADANG
}

\author{
Gamindra Jauhari ${ }^{1}$ \\ ${ }^{1}$ Program Studi Teknik Industri Sekolah Tinggi Teknologi Industri (STTIND) Padang \\ Email: gamindra_113@yahoo.com
}

\begin{abstract}
Cement Bags Division at PT. Semen Padang in Padang has an important division to produce a number of problem. Bags produced of two types, including sewing bag and pasted bag. Quality problems or quality in production has always been a complex problem in the process of production. The tolerance limit of $1.2 \%$ the company but many defects that over range becomes a major problem because over cost quality. This research was done because of the quality problems at the cement bags division PT. Semen Padang. This purpose study was to apply the Six Sigma method in reduce product defects.The result of applying six sigma calculate internal failure costs. Data processing and analysis techniques used in this study is the six sigma method (define, measure, analysis, improve and control). In the calculation capability sigma and DPMO (Defect per million opportunites) using six sigma calculator. The results of this study showed that based on calculations using six sigma method with the DMAIC approach (define, measure, analyze, improve and control) can reduce product defects and internal failure costs caused by the defective product.
\end{abstract}

Key Words: Six Sigma, DMAIC, Defect Products, Failure Costs.

\section{PENDAHULUAN}

PT Semen Padang merupakan pabrik semen tertua di Indonesia yang didirikan pada tanggal 18 Maret 1910 dengan nama NV Nederlandsch Indische Portland Cement Maatschappi (NV NIPCM). Pabrik mulai berproduksi pada tahun 1913 dengan kapasitas 22.900 ton pertahun. PT Semen Padang hampir $63 \%$ mendistribusikan semen melalui angkutan laut dan kemasan zak dan curah, sedangkan selebihnya menggunakan angkutan darat, dalam kemasan zak, big bag dan curah. Distribusi ke daerah pasar melalui angkutan darat seperti ke daerah Sumatera Barat, Tapanuli Selatan, Riau Daratan, Bengkulu, dan Jambi dikantongkan di Pabrik Pengantongan Indarung dan distribusi angkutan melalui laut dikantongkan di Pabrik Pengantongan Teluk Bayur.

Permasalahan mutu atau kualitas dalam produksi selalu menjadi hal yang komplek didalam perjalanan manajemen PT. Semen Padang. Divisi Pabrik Kantong yang berlokasi di jalan By Pass Km 10 Bukit Putus Padang mempunyai peranan penting untuk memproduksi sejumlah kantong bagi konsumen. Kantong yang diproduksi terdiri dari dua jenis, diantaranya sewing bag dan pasted bag. Kedua jenis ini dibedakan berdasarkan daerah pemasaran, biasanya untuk daerah pasar lokal Sumatera Barat kantong yang digunakan adalah jenis pasted bag, sedangkan untuk jenis sewing bag lebih diprioritaskan pada daerah penjualan yang berada diluar Sumatera Barat, terutama daerah yang jalur transportasinya mesti melalui laut. Hal tersebut disebabkan karena seringkalinya terjadi produk cacat (defect) di lantai produksi Pasted Bag yang belum terkendali.

Salah satu kebijakan yang dilakukan pabrik kantong semen PT. Semen Padang adalah produk yang bebas cacat dan sesuai dengan standar kualitas produk yang telah ditentukan perusahaan. Namun demikian, kesalahan produksi masih saja terjadi khususnya dalam proses produksi. Bentuk kesalahan produksi yang terjadi adalah masih adanya kantong rusak yang ditemukan pada saat proses produksi berlangsung maupun pada saat aktivitas inspeksi dilakukan terhadap produk akhir. Kantong Semen dinyatakan cacat/rusak apabila produk tidak 
sesuai dengan standar kualitas yang telah ditetapkan bagian Quality Control PT. Semen Padang.

Berdasarkan pengamatan awal yang dilakukan, masih terdapat jumlah cacat (defect) produksi yang cukup tinggi berada diluar batas toleransi perusahaan. Tingginya jumlah cacat produksi pada lini produksi pasted bag ini mengakibatkan meningkatnya biaya kualitas terutama biaya kegagalan internal (Internal Failure Costs).

Dari uraian diatas, maka dapat dirumuskan masalah yang melatarbelakangi penelitian ini, yaitu :

1. Bagaimanakah penerapan metoda six sigma dengan pendekatan DMAIC (Define, Measure, Analyze, Improve and Control) dalam pengendalian mutu atau kualitas untuk pengurangan produk cacat $($ defect $)$ ?

2. Seberapa besarkah biaya kegagalan internal yang didapatkan (Internal Failure Cost) setelah ditentukannya produk defect dengan metoda DMAIC (Define, Measure, Analyze, Improve, and Control)?

Sesuai dengan latar belakang dan perumusan masalah yang didapatkan maka tujuan dari penelitian ini adalah untuk mengaplikasikan penerapan metoda six sigma dengan pendekatan DMAIC (Define, Measure, Analyze, Improve and Control) dalam pengendalian mutu atau kualitas untuk pengurangan produk cacat (defect) dan menghitung besar biaya kegagalan internal (Internal Failure Cost)

\section{METODOLOGI PENELITIAN}

Jenis penelitian yang penulis lakukan adalah penelitian yang bersifat terapan (applied research), yaitu penelitian yang hatihati, sistematik dan terus menerus terhadap suatu masalah dengan tujuan untuk digunakan dengan segera untuk keperluan tertentu (Menurut Sedarmayanti,2002). Data dan sumber data yang digunakan yakni data sekunder. Data sekunder adalah data yang diperoleh secara tidak langsung dari lapangan. Data sekunder yang dibutuhkan dalam penelitian ini adalah laporan harga pokok produksi kantong semen, laporan aktifitas produksi yang terkait, dan lain-lain.Tahapantahapan penelitian yang dilakukan adalah:

\subsection{Studi Literatur}

Mencakup studi-studi tertentu untuk memperdalam dan mempertajam teori mengenai metoda six sigma degan pendekatan DMAIC.

\subsection{Pengumpulan Data}

Pengumpulan data diperoleh dengan cara wawancara langsung dengan pihak yang berwenang, melakukan pengamatan langsung dan mengumpulkan data yang berasal dari dokumen pihak perusahaan.

Secara umum, data yang diperlukan untuk menganalisa dan memecahkan masalah dalam penelitian ini adalah data sekunder, yakni :(1) data harga pokok produksi; (2) jumlah cacat; (3) laporan jenis cacat produk.

\subsection{Pengolahan Data}

Pengolahan data dilakukan dengan menggunakan metode six sigma dengan pendekatan DMAIC. Data yang digunakan adalah data variabel yaitu data yang berdasarkan karakteristik yang diukur secara sebenarnya.

Pada tahap ini, data yang diperoleh akan diolah dengan berpedoman pada landasan teori. Landasan teori yang akan digunakan dalam mengolah data, menganalisa, dan memecahkan masalah nantinya menghitung diantaranya:

a. Metoda six sigma pendekatan DMAIC (Define, Measure, Analyze, Improve dan Control).

b. Biaya kegagalan internal dihitung dari jumlah cacat masing - masing jenis kantong dikalikan dengan harga pokok produksi

\section{HASIL DAN PEMBAHASAN}

Berdasarkan pengolahan data yang telah dilakukan, maka didapatkan hasilnya sebagai berikut:

1. Melakukan Metoda Six Sigma dengan Pendekatan DMAIC (Define, Measure, Analyze, Improve, dan Control)

\section{1) Define}

a. Membuat flowchart dari proses produksi kantong semen pasted bag

Aliran proses pembuatan tube pada mesin tubing dapat dijelaskan seperti pada gambar berikut: 


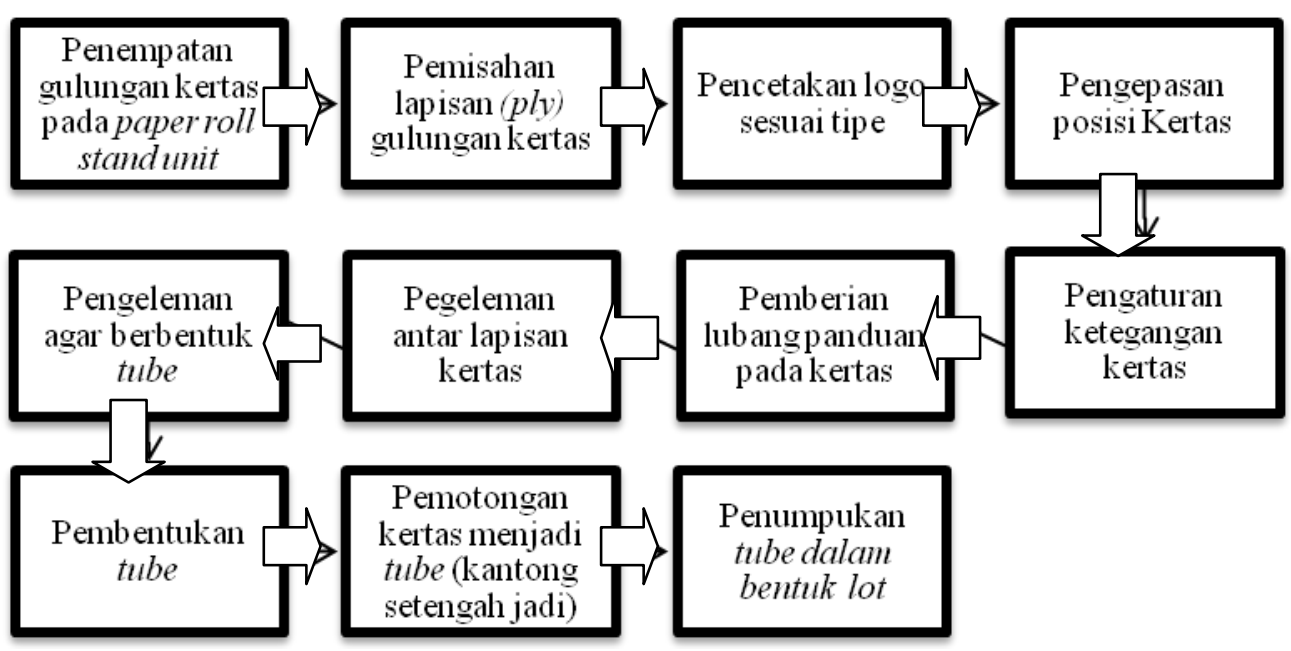

Gambar 4.1. Aliran Proses Pembuatan Tube Pada Mesin Tubing

Sumber: Pabrik Kantong Semen PT Semen Padang (2015)

Proses pembuatan tube atau kantong setengah jadi:

Aliran proses produksi kantong jadi pada mesin bottomer dapat dijelaskan seperti gambar berikut:

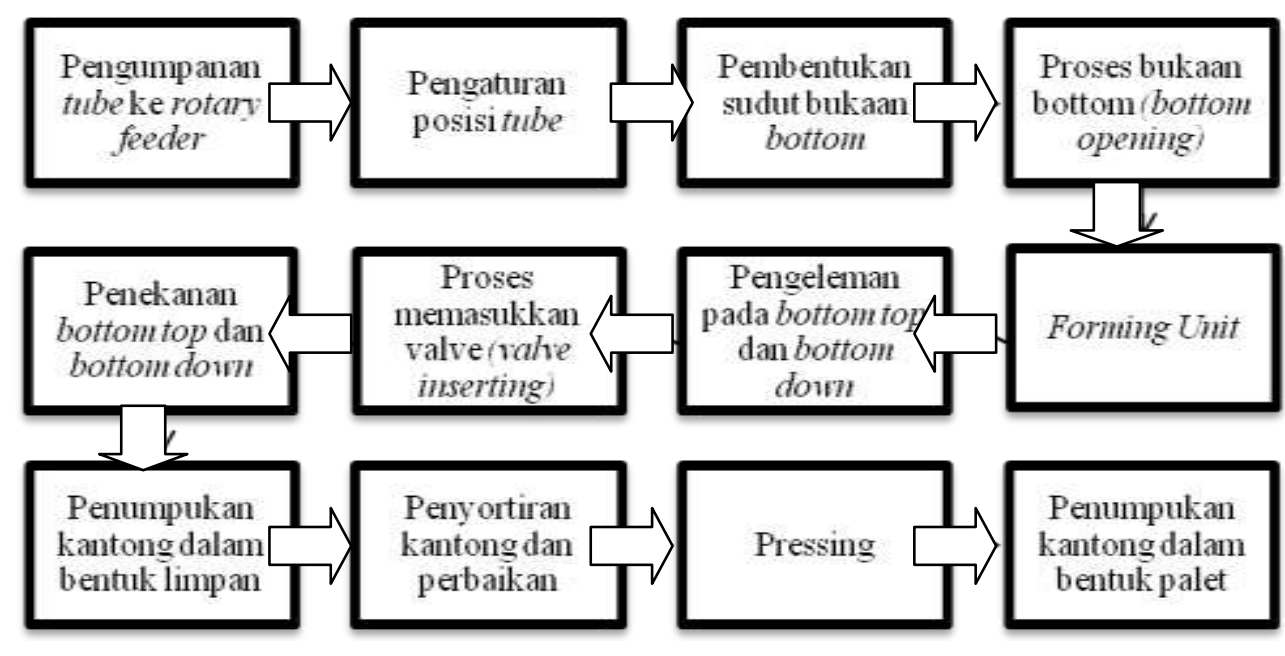

\section{Gambar 4.2 Aliran Proses Pembuatan Kantong Jadi Pada Bottomer.}

Sumber: Pabrik Kantong Semen PT Semen Padang (Data Sekunder, 2015) 
a. Membuat SIPOC Diagram

Diagram SIPOC proses produksi kantong semen PT. Semen padang dapat dilihat pada Gambar 4.3 sebagai berikut:

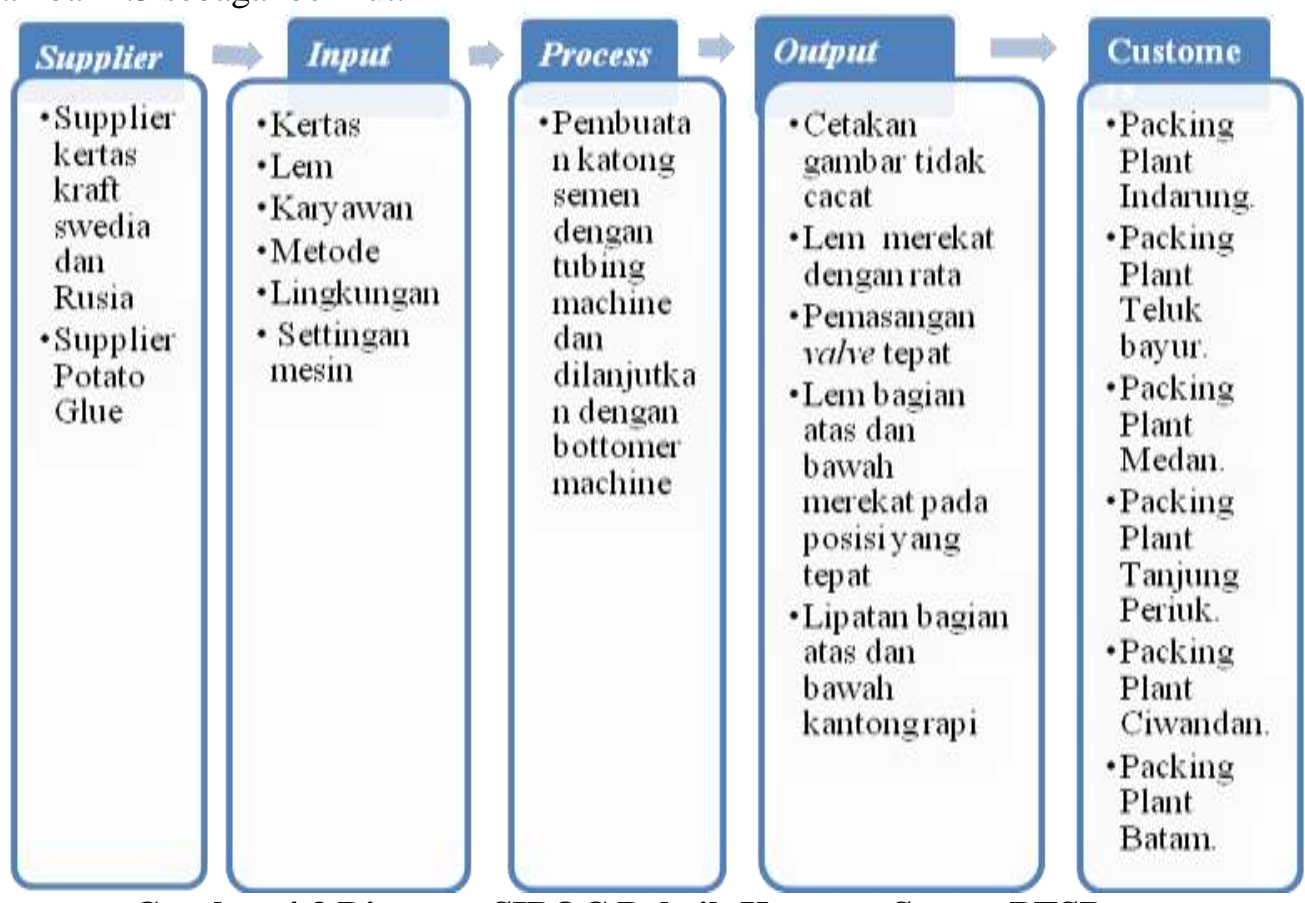

Gambar 4.3 Diagram SIPOC Pabrik Kantong Semen PTSP

2. Measure (Revisi Data Kantong Pasted Bag Cacat PTSP Bulan April 2015)

\begin{tabular}{|c|c|c|c|c|c|c|c|}
\hline No. & $\begin{array}{c}\text { Produksi } \\
\text { (Kantong) }\end{array}$ & $\begin{array}{c}\text { Cacat } \\
\text { (Kantong) }\end{array}$ & \% Cacat & P & CL & UCL & LCL \\
\hline 1 & 128,000 & 1,879 & $1.47 \%$ & 0.0147 & 0.0145 & 0.0155 & 0.0135 \\
\hline 2 & 172,000 & 2,466 & $1.43 \%$ & 0.0143 & 0.0145 & 0.0153 & 0.0136 \\
\hline 3 & 216,000 & 3,008 & $1.39 \%$ & 0.0139 & 0.0145 & 0.0152 & 0.0137 \\
\hline 4 & 212,000 & 3,180 & $1.50 \%$ & 0.0150 & 0.0145 & 0.0152 & 0.0137 \\
\hline 5 & 204,000 & 2,876 & $1.41 \%$ & 0.0141 & 0.0145 & 0.0153 & 0.0137 \\
\hline 6 & 180,000 & 2,700 & $1.50 \%$ & 0.0150 & 0.0145 & 0.0153 & 0.0136 \\
\hline 7 & 192,000 & 2,630 & $1.37 \%$ & 0.0137 & 0.0145 & 0.0153 & 0.0136 \\
\hline 8 & 164,000 & 2,460 & $1.50 \%$ & 0.0150 & 0.0145 & 0.0153 & 0.0136 \\
\hline 9 & 152,000 & 2,232 & $1.47 \%$ & 0.0147 & 0.0145 & 0.0154 & 0.0135 \\
\hline 10 & 204,000 & 3,066 & $1.50 \%$ & 0.0150 & 0.0145 & 0.0153 & 0.0137 \\
\hline 11 & 160,000 & 2,360 & $1.48 \%$ & 0.0148 & 0.0145 & 0.0154 & 0.0136 \\
\hline 12 & 160,000 & 2,400 & $1.50 \%$ & 0.0150 & 0.0145 & 0.0154 & 0.0136 \\
\hline 13 & 228,000 & 3,192 & $1.40 \%$ & 0.0140 & 0.0145 & 0.0152 & 0.0137 \\
\hline 14 & 96,000 & 1,344 & $1.40 \%$ & 0.0140 & 0.0145 & 0.0156 & 0.0133 \\
\hline 15 & 116,000 & 1,624 & $1.40 \%$ & 0.0140 & 0.0145 & 0.0155 & 0.0134 \\
\hline 16 & 72,000 & 998 & $1.39 \%$ & 0.0139 & 0.0145 & 0.0158 & 0.0131 \\
\hline Total & $\mathbf{2 , 6 5 6 , 0 0 0}$ & $\mathbf{3 8 , 4 1 5}$ & $\mathbf{1 . 4 5 \%}$ & $\mathbf{0 . 0 1 4 5}$ & & & \\
\hline
\end{tabular}

Sumber: Biro Pabrik Kantong PT. Semen Padang (Revisi,2015) 
Dari data kantong cacat yang telah direvisi maka didapatkan peta kendali $\mathrm{p}$ hasil revisi kantong pasted bag yang berada dalam batas kendali yaitu:

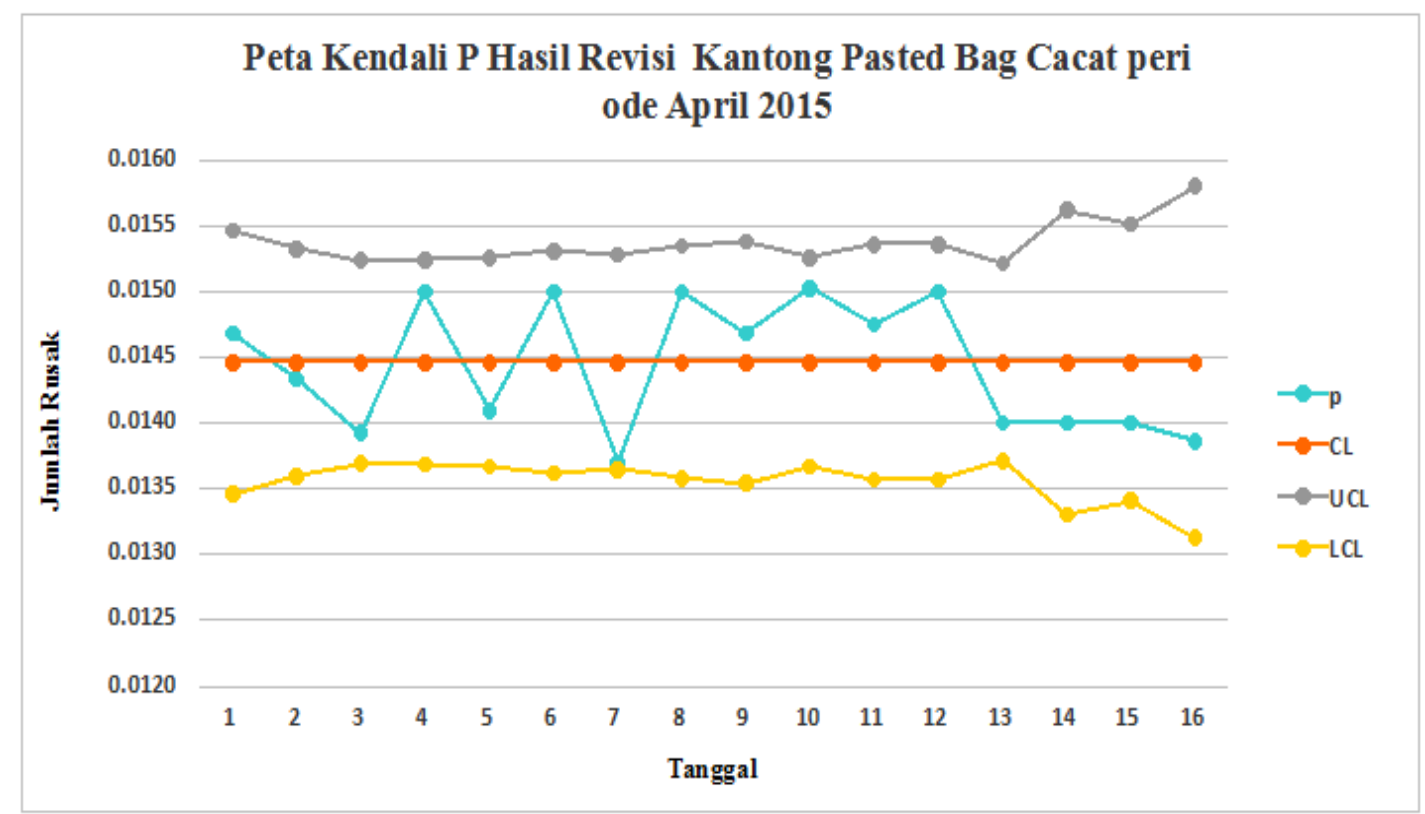

Gambar 4.5 Peta Kendali P Hasil Revisi Kantong Pasted Bag Cacat periode April 2015

3. Analyze

1. Mengelompokkan jenis cacat dengan diagram pareto

Setelah melakukan perhitungan

persentase cacat terhadap jenis kecacatan maka selanjutnya adalah pembuatan gambar diagram pareto yang dapat dilihat pada Gambar 4.7 berikut ini :

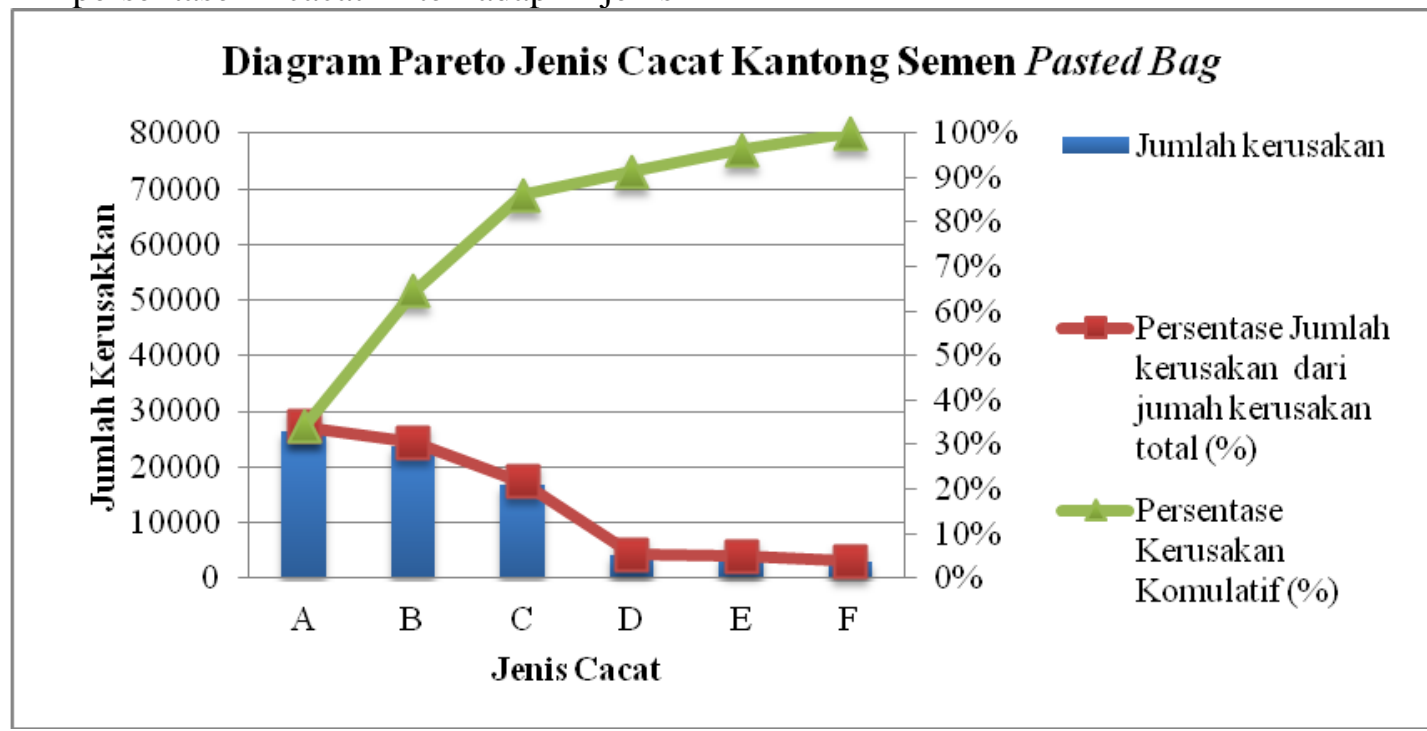

Gambar 4.7 Diagram Pareto Cacat Kantong Semen Pasted Bag

Keterangan:

A: Lipatan bagian atas dan bawah kantong tidak sempurna

B: Pemasangan valve atau katup tidak tepat

C: Lem pada bagian atas dan bawah kantong tidak rata

D: Cacat pada cetakkan logo
E: Tube tidak terpotong atau terpisah

F: Lem pada bagian badan tube tidak rata 
1. Failure Mode and Effect Analysis (FMEA)

Pemberian ranking pada analisis FMEA ini dengan menggunakan tabel penilaian FMEA dan dimasukan ke dalam rumus:

$R P N=S \times O \times D$

Dimana:

RPN : Risk Priority Number

$S$ : Tingkat keseriusan dari masingmasing efek

$O$ : Rating atau peluang muncul kejadian

$D$ : Tingkat atau rating deteksi dari kontrol

Berdasarkan cacat pada logo maka dapat dicari nilai RPN (Risk Priority Number) sebagai berikut:

a. Logo kabur

$$
\begin{aligned}
\mathrm{RPN} & =\mathrm{S} \times 0 \times \mathrm{D} \\
& =8 \times 2 \times 6 \\
& =96
\end{aligned}
$$

b. Komponen logo tidak lengkap

$$
\begin{aligned}
& \mathrm{RPN}=\mathrm{S} \times 0 \times \mathrm{D} \\
& =8 \times 5 \times 4 \\
& =160
\end{aligned}
$$

c. Posisi tidak tepat atau miring

$$
\begin{aligned}
& \mathrm{RPN}=\mathrm{S} \times 0 \times \mathrm{D} \\
& =7 \times 3 \times 7
\end{aligned}
$$

Tabel 4.13

Rekapitulasi Biaya Kegagalan Internal Kantong pasted Bag $50 \mathrm{~kg}$

\begin{tabular}{|c|c|c|c|c|}
\hline \multirow{2}{*}{ Bulan } & Type kantong & $\begin{array}{c}\text { Total Gagal } \\
\text { (kantong) }\end{array}$ & $\begin{array}{c}\text { Harga Pokok } \\
\text { (Rp/kantong) }\end{array}$ & $\begin{array}{c}\text { Total Cost } \\
\text { (Rp/kantong) }\end{array}$ \\
\hline April & Kantong Pasted Bag 50 & 77.295 & 2.113 & 163.324 .335 \\
\cline { 3 - 5 } Juli & Kg (2 Ply 85 gsm) & 48.004 & 2.213 & 106.232 .852 \\
\hline \multicolumn{2}{|c}{ Selisih } & $\mathbf{2 9 . 2 9 1}$ & & $\mathbf{5 7 . 0 9 1 . 4 8 3}$ \\
\hline
\end{tabular}

Sumber: Biro Pabrik Kantong PT. Semen Padang (Diolah, 2015)

Dari tabel di atas didapatkan pengurangan produk cacat sebsar 29.291kantong atau sama dengan $0.64 \%$ dengan pengurangan biaya kegagalan internalnya sebesar Rp. 57.091.483. Perbandingan produk cacat bulan April dan Juli 2015 serta pengurangan produk cacat dan biaya kegagalan internalnya

\section{KESIMPULAN}

Adapun kesimpulan dari penelitian ini adalah tercapainya tujuan penelitian yang dilakukan penilti sebagai berikut:
5. Control

Prinsip penyusunan rencana control adalah:

1. Menentukkan (karakteristik produk) yang harus diukur dan dikendalikan seperti pada spesifikasi kantong pada lampiran 5 .

2. Mengecekan setiap kali proses berlangsung (setiap pergantian shift)

3. Pengukuran dilakukan secara manual, dimana dilakukan saat penumpukkan pada mesin tubing. Penempatan kertas yang sesuai dengan jalurnya.

4. Menjelaskan siapa yang melakukan kontrol dan kendali selama proses sehingga karyawan yang ada saat shiftnya dapat bertanggung jawab penuh pada pekerjaannya.

5. Tindakan yang dilakukan jika kondisi tidak terkendali adalah menghentikkan proses produksi sebelum jumlah kantong cacat bertambah.

6. Menghitung Biaya Kegagalan Internal

Dari cacat yang didapatkan dihitung biaya kegagalan internal dengan menggunankan rumus:

IFC $=$ Jumlah cacat $\times$ harga pokok produksi

Dimana : IFC (Internal Failure Costs)
1. Penerapan metoda six sigma dengan pendekatan DMAIC (Define, Measure, Analyze, Improve, dan Control) hasilnya cukup baik untuk mengurangi produk cacat. Hal ini dapat dilihat dari data produk cacat yang diperoleh dari line IV pabrik kantong PT. Semen Padang (PTSP) pada bulan April 2015 sebesar 1,42\% (77.295 kantong) dan setelah diterapkannya metoda six sigma dengan pendekatan DMAIC (Define, Measure, Analyze, Improve, dan Control) pada bulan Juli 2015 diperoleh 
persentase cacat $0,78 \%$ (48.004 kantong) sehingga dapat mencapai tujuan dari metoda six sigma yaitu pengurangan produk cacat dengan persentase $0,64 \%$ (29.291 kantong cacat).

2. Dari hasil analisa perhitungan biaya kegagalan internal didapatkan bahwa bulan juli adanya penurunan biaya kegagalan internal dari persentase kecacatan bulan April 2015 1,42\% dengan biaya kegagalan internal Rp.163.324.335 menjadi 0,78\% pada bulan Juli 2015 dengan persentase kantong cacat dan biaya kegagalan internalnya sebesar Rp.106.232.852 sehingga didapatkan pengurangan biaya kegagalan internal adalah Rp.57.091.483. Jadi, dapat disimpulkan metoda six sigma dengan pendekatan DMAIC (Define, Measure, Analyze, Improve, dan Control) dapat mengurangi pemborosan biaya terutama biaya kualitas.

\section{DAFTAR KEPUSTAKAAN}

Anonim. Data-data, Laporan dan Arsip PT. Semen Padang

Ariani, D. W., Manajemen Kualitas, Andi Offset, Yogyakarta, 1999.

Ariani, D. W., Pengendalian Kualitas Statistik, Andi Offset, 2004.

Dermawan, D., Studi Aplikasi Pengendalian Mutu Produksi Kantong Semen Pada Unit Sewing Bag Divisi Pabrik Kantong PT. Semen Padang,
Universitas Sumatera Utara, Medan, 2007.

Doughlas C, Mortgomery, Introduction to Statistical Quality Control, Edisi VI, Jhon, Wiley and Sons Inc, Arizona State University, 2009.

Ervil, Riko, dkk, "Buku Panduan Penulisan Dan Ujian Skripsi”, STTIND Padang, Padang. 2012.

Hasan, I., Misbahuddin, Analisis Data Penelitian Dengan Statistik, Edisi II, Bumi Aksara, Jakarta, 2013.

Mitra, Amitava, Fundamentals of quality control and improvement, Edisi II, United States of America, America, 1998.

Pande, P.S., Robert P.N., Roland R.C., The Six Sigma Way-How GE, Motorola, and Other Top Companies are Honing Their Perfomance, Edisi II, Andi Offset , Yogyakarta, 2000.

Phylounna, N., Penentuan biaya langsung produksi kantong semen di pabrik kantong PT. Semen padang, Tugas Akhir, Jurusan Teknik Industri FT UNAND, Padang, 2006.

Tunggal, A. W., Manajemen Biaya, Penerbit Harvarindo, Jakarta, 2003.

Walpole, R. E., Raymond H.M., Ilmu Peluang dan Statistika untuk Insinyur dan Ilmuwan, Edisi IV, ITB Bandung, Bandung, 1995. 